\title{
Comparison of the Economic Feasibility between Conventional and Vacuum Drying for 4/4 Red Oak
}

\author{
Oxana Brenes-Angulo \\ Brian Bond \\ Earl Kline \\ Henry Quesada-Pineda
}

\begin{abstract}
Vacuum drying of wood is a method to reduce drying time and inventory; however, there is limited information regarding the economic feasibility for vacuum drying $4 / 4$ red oak compared with traditional drying methods. The benefits of this technology, mainly dramatically reduced drying times and higher flexibility, must be weighed against the higher initial capital investment. The goal of this project was to compare the economic feasibility, using capital budgeting techniques, of conventional drying and vacuum drying for $4 / 4$ red oak lumber. The analysis was conducted for two actual flooring manufacturers. Conventional drying for this analysis was considered to be air-drying plus kiln drying, which is commonly done with red oak. The vacuum technology considered used hot platens for heating the wood. Species, thickness, drying methods, and lumber demand compared, both drying methods (conventional and vacuum drying) were determined to be economically feasible. However, vacuum drying had a slightly higher net present value, cost-benefit ratio, and sensitivity analysis than conventional drying, making it a slightly better investment for drying $4 / 4$ red oak. The initial tied-up inventory and its respective cost in the conventional drying scenario represents an opportunity cost that can be recovered using vacuum drying. This recovered cost can result in freed capital that can be invested elsewhere to increase competitiveness.
\end{abstract}

$\mathrm{D}$ resulting in dimensionally stable lumber that can be cut to precise dimensions and machined more easily and efficiently and in more effective application of finishes (Jia 2006). Lumber is normally kiln dried in large batches prior to machining, which consumes a large percentage of the total manufacturing time. Drying times can vary greatly depending on the species, initial moisture content (MC), method of drying, and thickness of the stock. For example, 4/4 hardwood lumber can range from 4 to 30 days of drying time. When lumber is air-dried first, the total drying time is much longer. For example, air-drying red oak from green to 20 percent MC takes 60 to 120 days (Simpson 1991), even though the kiln drying time is reduced to 8 days.

In a very demanding market, a 1-day difference in lead time can improve the competitiveness of an industry. Consequently, any reduction in drying time can have great potential benefits (e.g., small batches, reduced costs, fewer inventory spaces, and faster throughput) for wood product manufacturers. In addition, the industry could benefit from a technology that allows it to dry lumber rapidly and in small batches, avoiding the need to dry mixed loads (different species at the same time), which can lead to a higher occurrence of drying defects and longer drying times, or to accumulate excessive lumber inventories (Rice et al. 1994). Research is needed to develop the best alternative for traditional lumber drying that would reduce lead times, allowing for order flexibility while maintaining quality and reducing costs.

Vacuum-drying technology has the potential to dry small batches of lumber in shorter cycle times, with quality results comparable to or better than conventional drying (Chen 1998). However, this technology has not been widely adopted (Chen 1998). Probable reasons for its limited

The authors are, respectively, Research Assistant, Professor, Professor, and Associate Professor, Dept. of Sustainable Biomaterials, Virginia Polytechnic Inst. and State Univ., Blacksburg (oxana9@vt.edu [corresponding author], bbond@vt.edu, kline@vt. edu, quesada@vt.edu). This paper was received for publication in July 2015. Article no. 15-00042.

C) Forest Products Society 2017.

Forest Prod. J. 67(7/8):455-462.

doi:10.13073/FPJ-D-15-00042 
implementation include higher initial cost of equipment, a perception of higher complexity of maintenance and operation than conventional drying, limited knowledge and support for the technology, and industry resistance to change (Chen 1998). Research on the economic feasibility of vacuum drying compared with traditional drying methods is extremely limited and focuses mainly on drying cost differences only. For example, Savard et al. (2004) determined that capital and operating costs were slightly lower with superheated steam vacuum drying compared with conventional drying. Therefore, companies wanting to invest in the new technology need updated and credible information to make decisions about its overall economic feasibility.

This research has a broader goal than that of Savard of evaluating the economic feasibility of vacuum drying for hardwood products manufacturing from a systems perspective. Specifically, to conduct capital budgeting techniques (comparisons of cash flow, net present value [NPV], and internal rate of return [IRR]), a cost-benefit and a sensitivity analysis were performed between conventional and vacuum drying for $4 / 4$ red oak lumber.

In this work, two actual companies (Manufacturers A and B) using conventional drying were modeled to determine the economic feasibility of conventional and vacuum drying. Two scenarios (conventional and vacuum drying) were created for each manufacturer. Manufacturer A dries wood for flooring and for selling dried lumber. Its main flooring products consist of 2.25- and 3.25-inch red and white oak prefinished and unfinished flooring. Manufacturer $\mathrm{B}$ is an industry that only dries lumber for flooring production. It produces unfinished and prefinished 2.25and 3.25-inch red and white oak flooring. However, only one production line was selected for each case study (3.25in. prefinished flooring) to reduce complexity. For this, onekiln capacity of Manufacturers A and B was reduced to meet the required demand for the single 3.25-inch prefinished flooring line.

Three major economic analysis techniques are commonly used to determine if the performance of a new investment project is economically viable: cash flow, NPV, and IRR (Newnan and Lavelle 1998). Ercan (2011) defined cash flow as "the difference between inflow and outflow." Zhang (2009) describes the NPV as "the total present value of all the investment spent on a project subtracted from all the revenue gained from the project over a certain time period. An interest rate is used to discount future spending or revenue into current value.' The IRR, according to Brealey and Myers (2003), Zhang (2009), and Ercan (2011), is defined as "the interest rate that can make NPV equal to zero."

Cost-benefit analysis is an important technique to use when comparing two projects where the initial investment is different (Yescombe 2014). Dreze and Stern (1987) defined cost-benefit analysis as "the examination of a decision in terms of its consequences or costs and benefits." A sensitivity analysis is another important technique when two projects are compared. Gottlieb (2010) defined a sensitivity analysis as "a way to determine the impact of changes in the input of the decision-making models."

This research shows a more flexible alternative to conventional drying that allows a business to dry small batches of lumber in very short times and with comparable or better quality than conventional drying. Vacuum drying's potential benefits, if successfully implemented, can help to increase the competitiveness of the US hardwood industry.

\section{Methodology}

Two examples of industrial wood flooring manufacturers utilizing 4/4 red oak were modeled to determine the impact of vacuum drying versus conventional drying on capital budget techniques (cash flow, NPV, and cost-benefit analysis). Both manufacturers had 2.25- and 3.25-inch red and white oak prefinished and unfinished flooring lines. However, only one production line was selected for each manufacturer (3.25-in. red oak prefinished flooring) to reduce the complexity in the capital budget comparisons. The actual manufacturing capacity was modified by reducing one of the kiln's capacity to meet the required demand for the single flooring line.

The thickness and species were chosen because of its difficulty to dry (longer drying times and higher quality control issues), its common use to manufacture goods, and the availability of manufacturers that use it. For this research, conventional drying refers to air-drying the lumber from its initial green state to 25 percent $\mathrm{MC}$ and then kiln drying to 8 percent MC (a common practice with $4 / 4$ red oak), while vacuum drying refers to drying lumber from the green state to 8 percent $\mathrm{MC}$ in a vacuum kiln. It was assumed that both drying facilities were new and that land, equipment, etc., had to be purchased.

\section{Drying costs}

The variables used to calculate the fixed and variable costs for each drying method (conventional and vacuum) were selected from the literature (Goulet and Ouimet 1968, Engalichev and Eddy 1970, MacMillen and Wengert 1978, Holmes and Bilek 1983, Fortin 1998, Govett et al. 2006, Redman 2011, Reeb 2011) and are presented in Tables 1 through 3 .

The majority of the data regarding drying times and costs (Tables 1 through 3 ) were gathered from manufacturers using vacuum and conventional drying technology. Data such as fences, lightning systems, and sprinkler systems were estimated using online information. Data regarding maintenance of boiler and kiln, maintenance and repair of air-drying yard, and thermal loss were gathered from the literature. All costs were reviewed by conventional and vacuum-drying manufacturers.

Once all the data were collected, the total drying cost and depreciation of the capital investment were calculated. The depreciation was calculated by the method of straight line (Gottlieb 2010). The electrical costs were calculated by multiplying operational days $\times$ run times $(h) \times$ number of fans $\times$ fan rating $(\mathrm{kW}) \times$ electrical cost $(\$ / \mathrm{kWh})$. The energy costs were calculated first by dividing the total heat energy $(\mathrm{kJ})$ by total BTUs in $1 \mathrm{~kJ}$. Then the total BTUs per charge used for drying were divided by the fuel consumption of natural gas (BTUs/MMcf), and then multiplied by the fuel cost (\$/MMcf). The initial raw material cost for the conventional drying scenario was calculated as follows: lumber in the air-drying yard takes 42 days and then 12.30 days in the kiln. Hence, $42 / 12 \approx 3.5$ turns or cycles of the kiln are possible during one cycle of air-drying. A detailed explanation of the formulas used to calculate total drying costs for both manufacturers can be found in the appendix section of Brenes Angulo (2014). 
Table 1.-Fixed and variable costs for conventional and vacuum-drying operations for Manufacturers $A$ and $B$.

\begin{tabular}{|c|c|c|c|c|}
\hline \multirow[b]{2}{*}{ Parameters } & \multicolumn{2}{|c|}{ Manufacturer A } & \multicolumn{2}{|c|}{ Manufacturer B } \\
\hline & Conventional drying & Vacuum drying & Conventional drying & Vacuum drying \\
\hline \multicolumn{5}{|l|}{ Fixed costs $(\$)$} \\
\hline Storage building & 662,097 & 522,020 & 575,000 & 322,766 \\
\hline Kiln (including, auxiliary equipment, boiler, installation) & $3,172,869$ & $7,215,000$ & $2,719,602$ & $6,734,000$ \\
\hline Stickers & 465,625 & 7,457 & 406,010 & 1,100 \\
\hline Pile roofs & 113,250 & - & 123,250 & - \\
\hline Pile bases, bolsters & 146,772 & - & 139,164 & - \\
\hline Air-drying alleys & 120,000 & - & 120,000 & - \\
\hline Fences & 46,378 & 6,388 & 35,381 & 4,111 \\
\hline Lighting systems (building) & 12,487 & 6,270 & 6,517 & 3,111 \\
\hline Air-drying drainage systems & 4,090 & - & 4,090 & - \\
\hline Sprinkler systems (building) & 23,236 & 6,490 & 20,200 & 5,430 \\
\hline \multicolumn{5}{|l|}{ Depreciation of storage building, kilns, stickers, pile } \\
\hline roofs, pile bases, lighting, drainage, and sprinkler systems & 31,035 & 56,808 & 29,666 & 58,343 \\
\hline Air-drying area (including space between the piles) & 165,000 & - & 90,000 & - \\
\hline Road area & 175,000 & - & 75,000 & - \\
\hline Area for buildings, kiln, boiler, etc. & 150,000 & 175,000 & 75,000 & 75,000 \\
\hline \multicolumn{5}{|l|}{ Variable costs } \\
\hline Maintenance of kilns and boiler (\$/yr) & 29,925 & 29,925 & 29,925 & 29,925 \\
\hline Maintenance and repair of yard (\$/yr) & 15,000 & - & 15,000 & - \\
\hline Snow removal $(\$ / \mathrm{yr})$ & 4,500 & - & 4,500 & - \\
\hline Forklift wage $(\$ / y r)$ & 114,000 & 171,000 & 114,000 & 171,000 \\
\hline Lumber graders $(\$ / y r)$ & 160,000 & 160,000 & 160,000 & 160,000 \\
\hline Wage for kiln operator and yard supervisor $(\$ / y r)$ & 67,000 & 67,000 & 67,000 & 67,000 \\
\hline Yearly raw material cost $(\$ / y r)$ & $12,794,145$ & $12,421,500$ & $11,247,600$ & $10,920,000$ \\
\hline Initial raw material cost $(\$)$ & $1,672,125$ & - & $1,848,000$ & - \\
\hline
\end{tabular}

\section{Capital budgeting techniques}

Once the drying costs had been calculated, four cash flow analyses were conducted: (1) conventional lumber drying, (2) vacuum drying for Manufacturer A, (3) conventional lumber drying, and (4) vacuum drying for Manufacturer B.

The cash flow analyses were conducted using Microsoft Excel each for an investment period of 20 years. According to Govett et al. (2006), 20 years is a good year analysis period for drying investments owing to the life expectancies of the equipment. The analysis was conducted using the drying cost data, lumber demand, and revenue for each manufacturer and drying method. The values associated with following activities were used to develop the cash flow analysis (Keown et al. 2006):

1. Operating activities

2. Investing activities

3. Financing activities

Table 2.-Parameters used for the calculation of electrical and energy costs for Manufacturers $A$ and $B$.

\begin{tabular}{|c|c|c|c|c|}
\hline \multirow{2}{*}{$\begin{array}{l}\text { Parameters used for the calculation } \\
\text { of electrical and energy costs }\end{array}$} & \multicolumn{2}{|c|}{ Manufacturer A } & \multicolumn{2}{|c|}{ Manufacturer B } \\
\hline & Conventional drying & Vacuum drying & Conventional drying & Vacuum drying \\
\hline No. of fans & 35 & - & 30 & - \\
\hline Annual electrical usage attributed to drying $(\mathrm{kWh} / \mathrm{yr})$ & $1,226,400$ & $1,892,160$ & $1,051,200$ & $1,766,016$ \\
\hline Electrical cost $(\$ / \mathrm{kWh})$ & 0.1 & 0.1 & 0.1 & 0.1 \\
\hline Thermal loss $(\%)$ & 65 & 30 & 65 & 30 \\
\hline Specific heat of water $\left(\mathrm{kJ} /\left(\mathrm{kg} \times{ }^{\circ} \mathrm{C}\right)\right)$ & 4.19 & 4.19 & 4.19 & $4.1 \mathrm{C}$ \\
\hline Heat of vaporization $(\mathrm{MJ} / \mathrm{kg})$ & 2.25 & 2.25 & 2.25 & 2.25 \\
\hline Specific gravity at fiber saturation point & 0.56 & 0.56 & 0.56 & 0.56 \\
\hline Water density $\left(\mathrm{kg} / \mathrm{m}^{3}\right)$ & 1,000 & 1,000 & 1,000 & 1,000 \\
\hline Energy to heat wood $(\mathrm{kJ})$ & $36,080,430$ & $11,894,648$ & $26,564,713$ & $9,251,392$ \\
\hline Energy to heat water $(\mathrm{kJ})$ & $3,146,514,207$ & $2,904,474,653$ & $1,853,331,445$ & $2,259,035,841$ \\
\hline Fuel cost, natural gas $(\$ / \mathrm{MMcf})$ & 4.10 & 4.10 & 4.10 & 4.10 \\
\hline
\end{tabular}




\begin{tabular}{|c|c|c|c|c|}
\hline \multirow{2}{*}{$\begin{array}{l}\text { Other important parameters for conventional and } \\
\text { vacuum-drying costs }\end{array}$} & \multicolumn{2}{|c|}{ Manufacturer A } & \multicolumn{2}{|c|}{ Manufacturer B } \\
\hline & Conventional drying & Vacuum drying & Conventional drying & Vacuum drying \\
\hline Annual interest rate $(\%)$ on loan & 2.25 & 2.25 & 2.25 & 2.25 \\
\hline $\begin{array}{l}\text { Tax rate to be applied to the total of taxable } \\
\text { values }(\%)\end{array}$ & 5 & 4 & 5 & 4 \\
\hline $\begin{array}{l}\text { Insurance rate applied to the total of insurable } \\
\text { values }(\%)\end{array}$ & 2 & 2 & 2 & 2 \\
\hline Sales revenue increase rate $(\%)$ & 2.8 & 2.8 & 2.8 & 2.8 \\
\hline Inflation rate $(\%)$ & 2.8 & 2.8 & 2.8 & 2.8 \\
\hline $\begin{array}{l}\text { Average drying degrades based on lumber value } \\
\text { (percentage as decimal) }\end{array}$ & 0.03 & - & 0.03 & - \\
\hline $\begin{array}{l}\text { Average daily volume of lumber on yard and in } \\
\text { kilns on any given day (MBF) }\end{array}$ & 4,000 & 303 & 4,355 & 222 \\
\hline Total capacity of kilns (BF) ${ }^{\mathrm{a}}$ & 455,000 & 150,000 & 402,000 & 140,000 \\
\hline No. of kilns & 7 & 15 & 6 & 14 \\
\hline Operational days & 365 & 365 & 365 & 365 \\
\hline Annual throughput (MBF/yr) & 13,650 & 13,650 & 12,000 & 12,000 \\
\hline Kiln cycles per year & 30 & 91.25 & 30 & 91.25 \\
\hline $\begin{array}{l}\text { Average length of kiln run (including loading and } \\
\text { unloading time) (d) }\end{array}$ & 12.3 & 4 & 12.3 & 4 \\
\hline Air-drying time (wk) & 6 & - & 6 & - \\
\hline Final drying time (hr) & 295 & 192 & 295 & 192 \\
\hline Volume air-dry yard (MBF) & 4,000 & - & 3,890 & - \\
\hline Initial moisture content $(\%)$ & 25 & 70 & 25 & 70 \\
\hline Final moisture content $(\%)$ & 8 & 8 & 8 & 8 \\
\hline
\end{tabular}

${ }^{a}$ Seven kilns of 65,000 BF for Manufacturer A; six kilns of 67,000 BF for Manufacturer B.

According to Keown et al. (2006), operating activities are those that either produce revenue or are a direct cost of producing a product or service. In our analysis, revenue refers to the value of the dried lumber through sales. Direct cost includes raw materials, operations, and energy costs. Investing activities include buying and selling noncurrent assets that will be used to generate revenues over a long period of time. Investment activities include buildings, sheds, stickers, kilns, and initial raw material for the airdrying yard. The financing activities can include information regarding the borrowing and repaying of money, issuing stock (equity), and paying dividends. For this project, this section was directed to the bank loan for the initial investment.

Assumptions regarding sales revenue, loan and interest rate on the loan, and air-drying initial raw material cost for the conventional scenario were made to conduct the cash flow analysis. Personal interviews with different banks (Wells Fargo and Freedom First) were carried out to determine the typical loan amounts and current interest rates. For this analysis, a loan of 80 percent of the requested amount with an interest rate of 2.25 percent was used. Other assumptions were the following: (1) sales revenue regarding only dried lumber had an increase rate of 2.8 percent per year; (2) for Manufacturer A, the bank loan for the capital investment for the conventional scenario was $\$ 6,928,929$ and for vacuum drying it was $\$ 7,938,624$; (3) for Manufacturer B, the bank loan for the capital investment of conventional drying was $\$ 6,237,215$ and for vacuum drying it was $\$ 7,145,518$; (4) an inflation rate for all costs was assumed to be 2.8 percent per year; and (5) the initial raw material cost, presented in Table 1, represents the cost of the initial amount of lumber needed in the air-drying yard to be able to operate the system. This initial amount of lumber helps the system start working before it reaches a steady state. In the case of vacuum drying, there is no airdrying: lumber is dried green to 8 percent of MC, which means that there is no need for initial raw material. The initial raw material cost for the conventional drying scenario was calculated as follows: lumber in the air-drying yard takes 42 days and then 12.30 days in the kiln. Hence, 42/12 $\approx 3.5$ turns or cycles of the kiln are possible during one cycle of air-drying.

The income before depreciation and taxes was calculated by subtracting operating costs from estimated sales. Then the profit before taxes and interest were calculated by subtracting depreciation from income before tax and depreciation. The tax rate was then applied to the profits before taxes, and the interest rate was applied to the loan. Finally, the net cash flow was obtained by adding cash flow from operating activities (net profit plus depreciation) and cash flow from financing activities (amortization). There is no cash flow from investment activities other than from year 0 (initial capital investment).

After completing the cash flow analysis for the two drying scenarios (conventional and vacuum drying) for each manufacturer, the values for NPV and IRR for vacuum and air-drying for each case study were compared using the following equations:

$$
\mathrm{NPV}=-C_{0}+\sum_{i=1}^{T} \frac{C_{i}}{(1+r)^{i}}
$$

and

$$
\mathrm{IRR}=-C_{0}+\sum_{i=1}^{T} \frac{C_{i}}{(1+r)^{i}}=0
$$

where 
$C_{0}=$ the initial investment,

$r=$ the interest rate,

$t=$ the year,

$T=$ the economic life of a system, and

$C_{i}=$ the revenue earned.

\section{Cost-benefit analysis}

The methodology proposed by Yescombe (2014) was used for the cost-benefit analysis for each scenario (conventional and vacuum drying) for Manufacturers A and B. The NPVs of both the costs (the original investment) and the benefits (the return on that investment) were calculated for each scenario (conventional and vacuum drying) for Manufacturers A and B. The NPV of benefits was calculated by adding the original investment plus the NPV at a 15 percent discount rate. The original investment was used as the NPV of costs. Then the cost-benefit ratio was calculated by dividing the NPV of benefits by the NPV of costs. The cost-benefit ratio was then compared between each scenario to determine which was economically better: the higher the ratio, the better the project (Yescombe 2014).

\section{Sensitivity analysis}

A sensitivity analysis for each scenario (conventional and vacuum drying) for Manufacturers A and B was conducted using the methodology proposed by Yescombe (2014). Two key parameters or sensitivities were selected according to their major costs: electrical and yearly raw material costs, resulting in two new cash flows: one raised the sensitivities by 10 percent, and the other reduced the sensitivities by 10 percent.

\section{Results}

The initial investment costs to run the drying operation (i.e., building, storage shed, fences, lightning, sprinkler, initial raw material, stickers, pile roofs, and air-drying alleys) are shown in Table 4 for conventional and vacuum drying for each manufacturer.

Manufacturer A's capital investments for conventional and vacuum drying were $\$ 6,928,929$ and $\$ 7,938,624$, respectively. Manufacturer B's capital investments for conventional and vacuum drying were $\$ 6,237,215$ and $\$ 7,145,518$, respectively. Differences in the capital investment for both scenarios are product of the kiln equipment costs. The kiln equipment costs for Manufacturer A were $\$ 3,172,869$ for conventional and $\$ 7,215,000$ (127\% more) for vacuum drying. The kiln equipment costs for Manufacturer B were $\$ 2,719,602$ for conventional and $\$ 6,734,000$ (148\% more) for vacuum drying. Vacuum kilns have smaller capacities than conventional kilns, so more vacuum kilns are needed to be able to satisfy the daily demand for both manufacturers. While the equipment capital costs are higher for the variables used in this project, they do not show which scenario and technology are most economically viable because these initial costs are calculated for a fixed time and not over a longer period of time as is done in the cash flow. Such cash flow analysis is presented further in the NPV analysis. The annual costs to run the drying operation (operational, maintenance, energy, and raw material) are shown in Table 5. The costs were collected from Manufacturers A and B. They represent the annual costs of drying lumber for each manufacturer.
Table 4.-Initial investments by Manufacturers $A$ and $B$.

\begin{tabular}{|c|c|c|c|c|}
\hline \multirow[b]{2}{*}{ Parameters } & \multicolumn{2}{|c|}{ Manufacturer A } & \multicolumn{2}{|c|}{ Manufacturer B } \\
\hline & $\begin{array}{l}\text { Conventional } \\
\text { drying }\end{array}$ & $\begin{array}{c}\text { Vacuum } \\
\text { without } \\
\text { air-drying }\end{array}$ & $\begin{array}{c}\text { Conventional } \\
\text { drying }\end{array}$ & $\begin{array}{c}\text { Vacuum } \\
\text { without } \\
\text { air-drying }\end{array}$ \\
\hline Land value $\left(\$ / \mathrm{ft}^{2}\right)$ & 490,000 & 175,000 & 240,000 & 75,000 \\
\hline Storage building (\$) & 662,097 & 522,020 & 575,000 & 322,258 \\
\hline $\begin{array}{l}\text { Kiln, auxiliary } \\
\text { equipment } \\
\text { (including boiler) (\$) }\end{array}$ & $3,172,869$ & $7,215,000$ & $2,719,602$ & $6,734,000$ \\
\hline Stickers $(\$)$ & 465,625 & 7,457 & 406,010 & 1,100 \\
\hline Pile roofs $(\$)$ & 113,250 & - & 123,250 & - \\
\hline Pile bases, bolsters $(\$)$ & 146,772 & - & 139,164 & - \\
\hline Air-drying alleys (\$) & 120,000 & - & 120,000 & - \\
\hline Fences $(\$)$ & 46,378 & 6,388 & 35,381 & 4,111 \\
\hline $\begin{array}{l}\text { Lighting systems } \\
\text { (building) (\$) }\end{array}$ & 12,487 & 6,270 & 6,517 & 3,111 \\
\hline $\begin{array}{l}\text { Air-drying } \\
\text { drainage systems (\$) }\end{array}$ & 4,090 & - & 4,090 & - \\
\hline $\begin{array}{l}\text { Sprinkler systems } \\
\text { (building) (\$) }\end{array}$ & 23,236 & 6,490 & 20,200 & 5,430 \\
\hline $\begin{array}{l}\text { Initial raw material } \\
\text { cost }(\$)\end{array}$ & $1,672,125$ & - & $1,848,000$ & - \\
\hline $\begin{array}{l}\text { Total initial } \\
\text { investment (\$) }\end{array}$ & $6,928,929$ & $7,938,624$ & $6,237,215$ & $7,145,518$ \\
\hline
\end{tabular}

Vacuum-drying operational costs were higher than conventional drying costs for both manufacturers $(17 \%)$. The reasons for the higher operational costs of vacuum drying are that the lumber dries faster, requiring more employees for the loading and unloading of the kiln to produce the same required volumes. Maintenance costs were approximated using data from Fortin (1998) because none of the manufacturers, suppliers, or users of the technology could provide more accurate information. Vacuum-drying energy costs were 47 and 117 percent more than conventional drying for Manufacturer A and Manufacturer B, respectively. Vacuum-drying electrical costs were 54 and 68 percent more than conventional drying for Manufacturer A and Manufacturer B, respectively. A possible reason for the higher energy and electrical costs in vacuum drying is that vacuum drying needed more kilns (15 for Manufacturer A and 14 for Manufacturer B) than conventional drying ( 7 for Manufacturer A and 6 for Manufacturer B). Vacuum-drying raw material costs were 3 percent less than conventional drying costs because

Table 5.-Total annual costs for conventional and vacuumdrying scenarios for Manufacturers $A$ and $B$.

\begin{tabular}{lccccc}
\hline \hline & \multicolumn{4}{c}{ Values $(\$ / \mathrm{yr})$} \\
\cline { 2 - 3 } & \multicolumn{2}{c}{ Manufacturer A } & & \multicolumn{2}{c}{ Manufacturer B } \\
\cline { 2 - 3 } \cline { 5 - 6 } Current costs & $\begin{array}{c}\text { Conventional } \\
\text { drying }\end{array}$ & $\begin{array}{c}\text { Vacuum } \\
\text { drying }\end{array}$ & & $\begin{array}{c}\text { Conventional } \\
\text { drying }\end{array}$ & $\begin{array}{c}\text { Vacuum } \\
\text { drying }\end{array}$ \\
\hline Operations & 341,000 & 398,000 & & 341,000 & 398,000 \\
Maintenance & 49,425 & 29,925 & & 49,425 & 29,925 \\
Energy & 162,370 & 238,728 & & 100,613 & 219,270 \\
Electricity & 122,640 & 189,216 & 105,120 & 176,602 \\
Yearly raw & & & & $11,247,600$ & $10,920,000$ \\
$\quad$ materials & $12,794,145$ & $12,421,500$ & & $11,843,758$ & $11,743,797$ \\
$\quad$ Total & $13,469,580$ & $13,277,369$ & & 11,80 \\
\hline \hline
\end{tabular}


Table 6.-Net present value (NPV) and internal rate of return (IRR) for Manufacturers $A$ and $B$.

\begin{tabular}{lcccccc}
\hline \hline \multirow{2}{*}{ Scenario } & \multicolumn{2}{c}{ Manufacturer A } & & \multicolumn{2}{c}{ Manufacturer B } \\
\cline { 2 - 3 } \cline { 6 - 7 } Conventional drying & NPV (\$) & IRR (\%) & & NPV (\$) & IRR (\%) \\
Vacuum drying & $11,820,997$ & 34 & & $10,641,532$ & 34 \\
\hline \hline
\end{tabular}

conventional drying initial raw material had a 3 percent degrade from the air-drying.

The NPV and the IRR were calculated using the values obtained from the net cash flow for each scenario: conventional and vacuum drying for Manufacturers A and B. Results are presented in Table 6. NPV was calculated using a discount rate, $r$, of 15 percent.

The NPV for Manufacturer A was $\$ 11,820,997$ and $\$ 11,860,638$ for conventional and vacuum drying, respectively. In the case of Manufacturer B, the NPV was $\$ 10,641,532$ for conventional drying and $\$ 15,712,609$ for vacuum drying. For both companies, conventional and vacuum-drying methods were found to be economically feasible. However, vacuum drying was shown to offer slightly better returns than conventional drying owing to a slightly higher value of the NPV. A project is considered economically feasible if NPV is positive, and a higher NPV represents a more economical viable project if more than one NPV is compared (Newnan and Lavelle 1998). The IRR for Manufacturer A was 34 percent for conventional and 32 percent for vacuum drying. For Manufacturer B, the IRR was 34 percent for conventional and 40 percent for vacuum drying. All scenarios were economically feasible at a discount rate of 15 percent.

In many situations, the IRR can lead to the same decision as the NPV, but there are also situations when the IRR may lead to different decisions from the NPV. Arshad (2012) concluded that when the two methods lead to different decisions, the NPV method tends to give better decisions. Arshad explains that the NPV is preferable when the projects are mutually exclusive because it reinvests the cash flow at the cost of capital, while the IRR is better when evaluating individual projects because the IRR reinvests at a calculated IRR. Therefore, for this study, values of the NPV were used as one of the factors for concluding which drying method was more economically viable.

However, a cost-benefit analysis was computed because of the inconsistencies between the NPV and IRR analysis to determine which scenario (conventional or vacuum drying) was more economically feasible. The NPV and IRR results are still presented so that readers can make more informed decisions based on the conclusions drawn in this work. Table 7 shows the cost-benefit analysis for conventional and vacuum drying for each manufacturer.
The cost-benefit ratio for Manufacturer A for conventional and vacuum drying was 1.31 and 1.34 , respectively. In the case of Manufacturer B, the cost-benefit ratio was 1.32 and 1.41 for conventional and vacuum drying, respectively. Vacuum drying had a higher cost-benefit ratio than conventional drying for both manufacturers, showing it to be a better economic alternative. According to Yescombe (2014), the higher the ratio, the better the project.

A sensitivity analysis was done to further investigate the moderate degrees of differences between conventional and vacuum drying for Manufacturers A and B. In the analysis, electricity and yearly raw material costs were raised by 10 percent and reduced to 10 percent. Table 8 shows the results of the sensitivity analysis for Manufacturers A and B.

In the case of raising the electrical and yearly raw material costs by 10 percent (Table 8), the NPV and IRR for conventional and vacuum drying for Manufacturer A were $\$ 3,141,609, \$ 3,614,458$, and 20 and 20 percent, respectively. The NPV and IRR for conventional and vacuum drying for Manufacturer B were $\$ 3,217,959, \$ 8,456,512$, and 21 and 28 percent, respectively. Furthermore, when reducing the electrical costs and yearly raw material costs by 10 percent, the NPV and IRR for conventional and vacuum drying for Manufacturer A were $\$ 20,008,351, \$ 20,106,818$, and 49 and 45 percent, respectively. In the case of Manufacturer B, the NPV and IRR for conventional and vacuum drying were $\$ 18,065,105, \$ 22,968,705$, and 49 and 53 percent, respectively. All scenarios were economically feasible at a discount rate of 15 percent. However, the NPV was higher in the vacuum-drying scenario for both manufacturers, indicating that vacuum drying is more economically viable than conventional drying in terms of a return of the initial investment.

The results from the NPV, cost-benefit ratio, and sensitivity analysis showed how the initial raw material costs significantly influenced the feasibility analysis. In conventional drying, there will always be 1,893 MBF more tied-up inventory each year for Manufacturer A and 1,730 MBF for Manufacturer B, representing an opportunity cost of $\$ 1,722,289$ and $\$ 1,574,664$, respectively. These cost reductions free up enough cash to pay off the capital investment of the vacuum kiln equipment or enough cash that could be invested elsewhere to grow the company. Our results agree with those of Apel et al. (2007), who established that reducing drying times would allow the industry to dry lumber in a faster way and that the reduction in drying times would mean a reduction in manufacturing cost, an increase in earnings, and a competitive advantage for the industry.

Furthermore, vacuum drying can also help to improve the performance of a flooring manufacturer by reducing drying lead times and tied-up inventory between each process in the manufacturing line while meeting customer demand. Brenes et al. (2015) demonstrated that vacuum drying has the potential to achieve shorter drying times, dry smaller

Table 7.-Cost-benefit analysis for conventional and vacuum drying for Manufacturers $A$ and $B$.

\begin{tabular}{|c|c|c|c|c|}
\hline \multirow[b]{2}{*}{ Cost-benefit analysis } & \multicolumn{2}{|c|}{ Manufacturer A } & \multicolumn{2}{|c|}{ Manufacturer B } \\
\hline & Conventional drying & Vacuum drying & Conventional drying & Vacuum drying \\
\hline (a) Net present value of benefits (\$) & $375,035,814$ & $376,066,132$ & $331,350,324$ & $350,995,057$ \\
\hline (b) Net present value of costs (\$) & $286,633,468$ & $281,579,224$ & $251,910,106$ & $248,948,384$ \\
\hline Cost-benefit ratio $[(a) \div(b)]$ & 1.31 & 1.34 & 1.32 & 1.41 \\
\hline
\end{tabular}


Table 8.-Sensitivity analysis of net present value (NPV) and internal rate of return (IRR) for conventional and vacuum drying for Manufacturers $A$ and $B$.

\begin{tabular}{|c|c|c|c|c|c|c|c|c|}
\hline \multirow[b]{3}{*}{ Parameters } & \multicolumn{4}{|c|}{ Manufacturer A } & \multicolumn{4}{|c|}{ Manufacturer B } \\
\hline & \multicolumn{2}{|c|}{ Conventional drying } & \multicolumn{2}{|c|}{ Vacuum drying } & \multicolumn{2}{|c|}{ Conventional drying } & \multicolumn{2}{|c|}{ Vacuum drying } \\
\hline & NPV (\$) & $\operatorname{IRR}(\%)$ & NPV (\$) & IRR $(\%)$ & NPV (\$) & IRR $(\%)$ & NPV (\$) & $\operatorname{IRR}(\%)$ \\
\hline \multicolumn{9}{|l|}{ Electrical and yearly } \\
\hline raw material costs raised $10 \%$ & $3,141,609$ & 20 & $3,614,458$ & 20 & $3,217,959$ & 21 & $8,456,512$ & 28 \\
\hline \multicolumn{9}{|l|}{ Electrical and yearly } \\
\hline raw material costs reduced $10 \%$ & $20,008,351$ & 49 & $20,106,818$ & 45 & $18,065,105$ & 49 & $22,968,705$ & 53 \\
\hline
\end{tabular}

loads, and achieve at least the same drying quality as conventional drying while servicing the market more efficiently. In conventional drying, it takes a long time to cycle through one batch of the same product (thickness and species), resulting in the need for more inventory to be held in case other products are demanded by customers. The total lead time associated with conventional drying increases the amount of inventory in the system and therefore the annual inventory costs. For vacuum-drying technology, total lead times are shorter, meaning that there is no need for large amounts of inventory in the system because the business is capable of cycling through all of the product possibilities much faster. Shorter drying times reduce inventory, leading to a reduction in the inventory costs. For example, orders placed for products that can be delivered with shorter lead times have a greater probability of being filled before the orders expire or change. Also, associating a dollar value to cycle time often highlights the true impact of manufacturing time on total cost to the company (Rust 2008). These potential benefits of vacuum drying could be used to increase the competitiveness of the hardwood industry in the United States and the international market.

\section{Conclusions}

When comparing the potential costs of building and operating a drying operation to meet the dry lumber needs of a flooring line, both conventional and vacuum-drying scenarios were found to be feasible for the scenarios studied. Vacuum drying was determined to be a slightly better investment than conventional drying for Manufacturers $A$ and $B$ based on the respective values of NPV: $\$ 11,860,638$ and $\$ 15,712,609$ for vacuum drying and $\$ 11,820,997$ and $\$ 10,641,532$ for conventional drying. Vacuum drying was also shown to be a slightly better economic alternative for Manufacturers A and B with costbenefit ratios of 1.34 and 1.41 compared with 1.31 and 1.32 for conventional drying. Also, vacuum drying was more economically feasible when raising or reducing the electrical and the yearly raw material costs by 10 percent. The initial tied-up inventory and the respective cost in the conventional drying scenario represents an opportunity cost for the vacuum-drying scenario that can be invested elsewhere to grow the company. In addition to being the better investment, vacuum drying can help the performance of a flooring manufacturer by reducing drying lead times and tied-up inventory between each process of the manufacturing line while meeting customer demand (Brenes et al. 2015). While these results are limited based on the inputs used in the model and may differ when these inputs change, they clearly indicate that vacuum-drying technology can be a financially viable option for drying large quantities of $4 / 4$ lumber and thus a potential technology for improving the competitiveness of the US hardwood industry.

\section{Acknowledgment}

This project was funded by the Wood Education and Resource Center (WERC).

\section{Literature Cited}

Apel, W., J. Yong-Li, and V. Walton. 2007. Value stream mapping for lean manufacturing implementation. BSc thesis. Worcester Polytechnic Institute, Worcester, Massachusetts.

Arshad, A. 2012. Net present value is better than internal rate of return. Interdiscip. J. Contemp. Res. Bus. 4(8):211.

Brealey, R. A. and S. C. Myers. 2003. Capital Investment and Valuation. 7th ed. McGraw-Hill, New York. 558 pp.

Brenes, O., B. Bond, E. Kline, and H. Quesada-Pineda. 2015. The impact of vacuum-drying on efficiency of hardwood products manufacturing. BioResources J. 10(3):4588-4598.

Brenes Angulo, O. M. 2014. The impact of vacuum-drying on efficiency of hardwood products manufacturing. Msc thesis. Virginia Polytechnic Institute and State University, Blacksburg.

Chen, Z. 1998. Primary driving force in wood vacuum drying. PhD dissertation. Virginia Polytechnic Institute and State University, Blacksburg.

Dreze, J. and H. Stern. 1987. Handbook of Public Economics. Vol. 2. A. J. Auerbach and M. Feldstein (Eds.). Elsevier Science Publishers, North-Holland. 1,106 pp.

Engalichev, N. and W. E. Eddy. 1970. Economic analysis of lowtemperature kiln in processing softwood lumber for market. Cooperative Extension Service, University of New Hampshire, Durham. 107 pp.

Ercan, N. 2011. A decision support tool for feasibility assessment of hydro electrical power plant projects. MS thesis. Middle East Technical University, Ankara, Turkey.

Fortin, Y. 1998. Drying under vacuum. www.valuetowood.ca/imports/ pdf/en/tech_profiles/TP-06-01E_VLavoie_Drying_English.pdf. Accessed August 25, 2012.

Gottlieb, I. 2010. Next Generation Excel: Modeling in Excel for Analysts and MBAs. Wiley, Singapore.

Goulet, M. and M. Ouimet. 1968. Determination of costs in wood seasoning. University of Laval Tech Note No. 5. University of Laval, Quebec. $52 \mathrm{pp}$.

Govett, R., S. Bowe, R. Dramm, S. Bratkovitch, and T. Mace. 2006. DRYFEAS Lumber Kiln Drying Operation Financial Feasibility Analysis Spreadsheet: Program User's Manual. USDA Forest Service Wood Education and Research Center of Princeton, West Virginia. 49 pp.

Holmes, S., G. B. Harpole, and E. Bilek. 1983. DEP: A computer program for evaluating lumber drying costs and investments. General Technical Report FPL-37. USDA Forest Service, Forest Products Laboratory, Madison, Wisconsin. $23 \mathrm{pp}$.

Jia, D. 2006. Numerical and experimental study of heat and mass transfer in microwave drying of hardwood. MSc thesis. University of New Brunswick, Fredericton. 134 pp.

Keown, A., J. Martin, W. Petty, and D. Scott. 2006. Foundations of Finance: The Logic and Practice of Financial Management. 5th ed. Pearson Prentice Hall, Upper Saddle River, New Jersey. 585 pp. 
MacMillen, J. and E. Wengert. 1978. Drying eastern hardwood lumber. www.fpl.fs.fed.us/documnts/usda/ah528.pdf. Accessed May 15, 2014.

Newnan, D. G. and J. P. Lavelle. 1998. Engineering Economic Analysis. 7th ed. Engineering Press, Austin, Texas. 756 pp.

Redman A. 2011. Evaluation of super-heated steam vacuum drying viability and development of a predictive drying model for Australian hardwood species. www.fwpa.com.au. Accessed August 25, 2012.

Reeb, J. 2011. Compare costs of different fuels for drying lumber. http:// ieeexplore.ieee.org/stamp/stamp.jsp?tp=\&arnumber $=6017907 \&$ isnumber $=6017605$. Accessed September 12, 2012.

Rice, B., J. Howe, R. S. Boone, and J. L. Tschernitz. 1994. Kiln drying lumber in the United States: A survey of volume, species, kiln capacity, equipment, and procedures. www.fpl.fs.fed.us. Accessed September 12, 2013.

Rust, K. 2008. Using Little's Law to estimate cycle time and cost. In:
Proceedings of the 40th Conference on Winter Simulation, Miami, Florida. pp. 2223-2228. DOI:10.1109/WSC.2008.4736323

Savard, M., V. Lavoie, and C. Trembala. 2004. Technical and economical assessment of superheated steam vacuum drying of northern red oak. In: COST E15 Conference, April 22-24, 2004, Athens, Greece. 10 pp.

Simpson, W. T. 1991. Dry Kiln Operator's Manual. Forest Products Laboratory, Madison, Wisconsin.

Yescombe, E. R. 2014. Principles of Project Finance. 2nd ed. Academic Press, Amsterdam. 560 pp. www.sciencedirect.com/science/book/ 9780123910585 Accessed November 1, 2015.

Zhang, Y. 2009. Sustainability oriented feasibility model for construction decision making: Water recycling cases in buildings. MS thesis. University of Toronto. 